\title{
Scaling-Up Antiretroviral Therapy in Tanzania: Perspectives of Users
}

\section{Randolph Quaye*}

Ohio Wesleyan University, Delaware, Ohio, United States

\begin{abstract}
Introduction: Several African countries, in response to the $2015 \mathrm{WHO}$ guidelines recommending that all diagnosed as HIV positive be enrolled in Antiretroviral Therapy (ART), have introduced treatment centers in an attempt to reach that population. Tanzania has been in the forefront of this effort. The HIV prevalence there is $5.9 \%$ for those $15-49$ years of age. Such a high prevalence rate can negatively affect the economic development of Tanzania. This paper explores the perspectives of a targeted population of Tanzanian individuals living with HIV, and examines their selfperception and the ways they manage their illness.
\end{abstract}

Method: The study was conducted in Dar es Salaam among a population using ART. Two hundred individuals were interviewed at four treatment centers. Based upon systematic review of the literature on self-management of people living with HIV, the author developed specific questions that explored the respondents' views on self-management, adherence to ART, their stigmatizing by others, and their views about condom and about the overall attitudes of their health care providers.

Results: A majority of respondents reported learning about their HIV status by accident through voluntary testing. About eighty-five reported living with HIV for the past fifteenyears. We found that $68.5 \%$ have not informed their family members or significant others about their HIV status. Overwhelmingly, they were opposed to free distribution of condoms and preferred abstinence as the first line of defense against the disease. While majority of respondents received care from designated government and private clinics, some mentioned the need to provide more ART services.

Conclusion: About half of the respondents reported that the services they received were at the level they expected but they argued that better management of staff time and greater staff sensitivity toward how the patient are perceived would have helped them better manage their treatment options. Several described the lack of privacy at the clinics, and some questioned whether care would be better handled through other means. The sample for this study is not a random sample of the entire population, in that all of them have tested HIV-positive and were receiving ART from a specific health facility. Our findings suggest that ART is improving the lives of Tanzanians.

Keywords: ART; Tanzania; Stigma; Adherence; HIV/AIDS

\section{Introduction}

The goal of the U.S. Presidential Emergency Fund for AIDS Relief (PEPFAR) was to "promote greater global investments and programmatic impact in the fight against AIDS". Its key objectives were, among other things, work with partner countries, donor nations, civil society and people with HIV to effectively mobilize, coordinate and efficiently utilize resources to expand high impact strategies to save lives [1]. Since the first three AIDS cases in Tanzania in 1983, the HIV epidemic has spread to all sectors of the population. Tanzania is facing its most critical health and development crisis to date.

Of the 38 million Tanzanians, an estimated 1.5 million individuals have HIV. The HIV prevalence is $5.9 \%$ for $15-49$ years. The female prevalence is $6.2 \%$, compared with $3.9 \%$ for men [2]. Such prevalence rates can impact negatively on the economic development of Tanzania. After all, HIV/AIDS burdens the communities of both poor and affluent. It renders families vulnerable, ends marriages, and leads to high numbers of children and adults orphaned or abandoned by those disabled or deceased due to the disease, or taken from them by others. It can cause "profound disruption to people's lives and identity" [3].

As eloquently pointed out by Russell “Self-management oflong-term illness is a complex, dynamic and interactive process, involving practical tasks, psychological and social adjustment. The work of managing illness needs recognizing symptoms, taking treatment, adopting healthier behaviors, activating resources, and the more complex process of living with the condition." The well-known concept, "therapeutic citizenship" is employed in this paper to gauge the perspectives of those living with HIV/AIDs among a selected group of patients in Dar es Salaam, Tanzania. By therapeutic citizenship, the author employs the definition used by [3].

According to them, "The concept of therapeutic citizenship involves our analysis of people's self-management of HIV." As they argue further, it includes experiences such as:

(a) A near-death experience followed by HIV diagnosis.

(b) Counseling processes and the fashioning of new perceptions of self-identities.

(c) A sense of belonging to a group; strategies to access resources and treatment and that ability to [empower] oneself [3].

The objectives of our study are:

- To explore the perspectives of people living with HIV on selfmanagement;

- To explore their attitudes on condom use;

*Corresponding author: Randolph Quaye, Ohio Wesleyan University, Delaware, Ohio, United States, Tel: 7403683833; E-mail: rkquaye@owu.edu

Received August 27, 2018; Accepted September 28, 2018; Published October 05, 2018

Citation: Quaye R (2018) Scaling-Up Antiretroviral Therapy in Tanzania: Perspectives of Users. J AIDS Clin Res 9: 777. doi: 10.4172/2155-6113.1000777

Copyright: () 2018 Quaye R. This is an open-access article distributed under the terms of the Creative Commons Attribution License, which permits unrestricted use, distribution, and reproduction in any medium, provided the original author and source are credited. 
- To assess their views on whether they have been successful in adhering to their treatment options;

- The role of stigmatization in their treatment option, and

- The role of social networking in managing their condition.

\section{Methods}

The study was conducted in Dar es Salaam, Tanzania's largest city, and also one of Tanzanian's 26 administrative regions. It has the second highest HIV prevalence in Tanzania's regions (9.3\%) against a national average of 5.7\% [4]. The study was conducted of Dar Es Salaam in four districts: Kinondoni, Temeke, Kigamboni, and Illala. They were chosen for interview convenience and also because they had more than twentyfive health facilities where ART services are provided. Two hundred participants were interviewed, fifty from each location.

The interview questions were translated into Swahili, and the results transcribed and translated back into English. The interview questions were grouped under five headings: demographic information about respondents, namely their age, marital status, gender, education, income, and religious affiliation. Based upon systematic review of the literature on self-management of people living with HIV/AIDS, specific questions were developed that explored their perspectives on self-management, their adherence to ART, stigmatization of their conditions, and their views on condom use and on the attitudes of health care providers.

\section{Results}

Two hundred individuals were interviewed with 50 selected from each of the 4 districts. The demographic profiles of the respondents are distributed as follows:

In response to the question, "When did you learn about your HIV status?" 85\% reported that they were infected between 1991-2018, 51\% of them between 2001-2010.

When respondents were asked about how they learned about their HIV status, $62 \%$ reported learning by accident. $38 \%$ reported learning about their status by visiting a Counseling and Treatment Center (VCT).

Overwhelming majority (91\%) reported that they have been attending ART clinics for an average of five years or more. About half have followed their ART regimen closely soon after learning about their HIV status. The other half only started when they became critically ill while pregnant.

When respondents were asked if they had informed their relatives or significant others about their HIV status a large majority (68.5\%), reported they have concealed their HIV status from their family members. Only $31.5 \%$ reported they have notified their relatives. The interview also asked respondents to rate their adherence to the antiretroviral regimen on a Likert scale of 1 to 5 with 5 (very poor), 4 (poor), 3 (fair), 2 (very good) and 1 as (excellent). The results indicated that only $5 \%$ rated their adherence as very poor, $15 \%$ as poor, $50 \%$ as fair, $15 \%$ as very good and $15 \%$ as excellent.

To ascertain behavior changes in response to the respondents' action to their HIV status, we asked, "What other precautions have you taken since learning about your HIV status?" $61 \%$ of respondents reported that they routinely use condom during sex and $16.5 \%$ reported abstaining from sex. On the other hand, $22.5 \%$ reported that they had not changed their behavior.

As discussed by Cort and Tu one likely outcome for individuals living with HIV is have to cope with this social stigma attached to the disease. Their research suggests that a powerful connection exists "between HIV-positive individuals' experiences with HIV stigma beliefs and protective sexual behavior". In their thought- provoking paper, Cort and $\mathrm{Tu}$ argue that, contrary to the prevailing view that the stigmatized, as the targets of the HIV stigma belief system, are less likely to practice protective sexual behavior [5]. Their study shows that at the very least, there are changes in the way patients with HIV approach their sexual practices.

Others have argued that scholars have not developed a theoretical explanation for how those who are "infected and uninfected with HIV develop stigmatizing discourses" to examine how being stigmatized can impact on self-management of the disease [5]. We asked series of questions aimed at exploring this phenomenon. We first asked our respondents how knowledgeable they are about their health condition. A large majority of our respondents (75\%) reported that they were indeed knowledgeable about their own health. Only $10 \%$ said they were not clear about their health conditions [6].

We then asked them to rate their self-management of their condition. Thirty-six percent rated their self-management as "very good", $35.5 \%$ rated it as "good" $11 \%$ as little good and $17.5 \%$ answering "not good at all". On the question, "how often have you missed your ART dose? $53.5 \%$ said seldom, $15 \%$ said, less often. About one third responded they have missed their ART dose". On the question,"How often has the dosage been changed?" More than half (53.5\%) responded by saying very often, $15 \%$ said less often and $31.5 \%$ responded, seldom. On the question, "How often do you go to the clinic for your ART?", about half reported once a month with almost half receiving their medication at home through the home-based care program. Furthermore, our respondents visiting the clinic reported that $15 \%$ of them have missed their appointment once, $4.5 \%$ twice and over two thirds have not missed their appointments at all (67\%).

When the slight majority of respondents were asked to explain under what circumstances they have not been able to pick up their medications on time or on regular basis, about half mentioned the difficulty of not having money to cover their bus fare to the clinic, $13.5 \%$ mentioned the distance to the health facilities and about 8 percent mentioned being sick or the weather (Table 1).

\section{Stigma}

Stigma is an ideology or belief system in which people claim that those infected with a disease are different from those in "normal" society who are uninfected. Cort and Tu claim that "there is a tendency in everyone-infected or non-infected-to place themselves and those they identify with into an in-group and those they perceive as different or alien into an out-group through a social process known as "splitting"... the consequence of splitting and projection is that stigmatizers use stigma beliefs as an emotional response to a danger they sense from HIV" [5].

Contrary to our general expectation that HIV patients would feel stigmatized by the society they live in, our findings however suggest that was not the case. As a matter of fact, $90 \%$ of our respondents responded that they did not feel stigmatized by their society. This is a very interesting discovery and is generally consistent with the observation made by Cort and Tu. They have argued that instrumental stigma, the misplaced fear of infection through everyday contact with those infected by HIVand culture as a blueprint that governs norms, values and ways of thinking that will have a major impact on how individuals relates to, and perceives how HIV individuals are treated andstigmatized. In a nutshell, Cort and Tu hypothesized that in countries with high 


\begin{tabular}{|c|c|}
\hline \multicolumn{2}{|c|}{ Age Range } \\
\hline $17-21$ & $15 \%$ \\
\hline $22-26$ & $45 \%$ \\
\hline $27-31$ & $25 \%$ \\
\hline $32+$ & $15 \%$ \\
\hline \multicolumn{2}{|c|}{ Gender } \\
\hline Male & $36.50 \%$ \\
\hline Female & $63.50 \%$ \\
\hline \multicolumn{2}{|c|}{ Education } \\
\hline Primary/Secondary & $71.50 \%$ \\
\hline Technological/Vocational & $22 \%$ \\
\hline Post-Graduate & $6.50 \%$ \\
\hline \multicolumn{2}{|c|}{ Marital Status } \\
\hline Married & $60 \%$ \\
\hline Single & $26 \%$ \\
\hline Divorced & $14 \%$ \\
\hline \multicolumn{2}{|c|}{ Religion } \\
\hline Protestant & $11 \%$ \\
\hline Muslim & $47.50 \%$ \\
\hline Catholics & $36 \%$ \\
\hline Other & $5.50 \%$ \\
\hline \multicolumn{2}{|c|}{ Monthly Income } \\
\hline $0-40,000 T Z$ & $41 \%$ \\
\hline $41-50,000$ & $20.50 \%$ \\
\hline $51-60,000$ & $30 \%$ \\
\hline $61,000+$ & $8 \%$ \\
\hline Note : $\$ 1=2260 \mathrm{TZ}$ & \\
\hline
\end{tabular}

HIV prevalence, e.g. (Tanzania and countries in Southern Africa) the degree of stigmatization is less than in those countries with low-HIV prevalence (e.g.,West Africa). Indeed, our own respondents mentioned that the reason they experience less stigmatization is because HIV/ AIDS has affected very family in Tanzania so people treat it like any other disease.

Our respondents also mentioned that because many have not disclosed their HIV status and the ART treatment is so effective that it is difficult to tell if someone is affected or not. For the $10 \%$ who did report being stigmatized, they mentioned that they experience stigmatization from health care providers (nurses) and from their relatives because they are isolated from community activities. Indeed, two-thirds of our respondents reported that they have had good relationship with health care providers who act as their advocates at all time. About $17 \%$ reported that they have had bad experiences with health care providers. They surmised that health care providers have been rude to them, blaming them for their HIV status. In response to a question, "how will you characterize your dealings with health care workers?" $34 \%$ said it was good, $23.7 \%$ reported it was bad and $42.5 \%$ were neutral. We also assessed whether they were satisfied with the health services in general in their respective districts. Approximately, $80 \%$ reported they were satisfied with the health services they received, while $12 \%$ reported they were inadequate or bad.

We asked our respondents some of the coping strategies in dealing with their HIV status. Majority mentioned that religion has proven to have been one of the effective methods they have employed to deal with their health status. Some reported that religion provides them with asense of hope and it is their religious commitment for the future that provides them with financial and social support. About half also mentioned they are emotionally supported by their family. On the question, "How can the health services be improved?" the respondents mentioned the need for health facilities to have adequate health workers in these facilities. They also mentioned the desire for easy and free access to nutritional meals as some of them are not able to afford them. They recommended building health treatment centers in each ward to avoid the transportation costs that some of them currently incur to get to treatment.

When we asked respondents what lessons they have for those not afflicted with the disease, about $65 \%$ called for abstinence and $35 \%$ recommended the use of condoms. When asked if condoms should be freely be made available for ages 14 and above, more than two thirds of the respondents reported no. About $25 \%$ said yes as it will prevent the spread of the disease.

They also suggested that the services be located near where people live and that income-generating activities be prioritized as well.

\section{Discussion}

This paper has examined the perspectives of individuals with HIV/AIDS and their participation in ART program. The majority of respondents reported learning about their HIV status by accident. What was striking was that about eighty-five percent have been living with HIV for the past 15 years, showing the success of the ART program and the respondents' adherence to the treatment regimen. Our findings suggest that $68.5 \%$ have not informed their family members or significant others about their HIV status, a potential reason for the spread of HIV. This strongly suggests the need for greater efforts about the importance of VCT clinics and other important campaigns to combat this HIV epidemic. An equal number of respondents were opposed to free distribution of condoms and preferred abstinence as the first line of defense against the disease. While a majority of respondents received care from designated government and private clinics, some mentioned the need for expansion of home-based care. After all, homebased care will arrest their problems with transportation costs and will ensure greater efficiency and confidentiality for patients seeking treatment. Those interviewed believed they have the right to HIV treatment, but few reported that they were willing and able to contribute financially to their own health care.

\section{Conclusion}

About half of the respondents reported that the services received were at the level expected but argued that better management of staff time and greater sensitivity toward how the patients are perceived would have helped them better manage their treatment options. Several respondents described the lack of privacy at these clinics, and some questioned whether care would be better handled through home visits, as this would guarantee more privacy. The sample for this study is different from a random sample of the entire population in that all of them have tested HIV-positive and were receiving care from a specific health facility. The geographically limited sample size makes generalizations to the entire Tanzanian population difficult. Nevertheless, our findings add further evidence to the impact of the ART program in improving the lives of Tanzanians.

\section{Acknowledgment}

The author is grateful to all the study participants for sharing their experiences with the research team I am indebted to J. Mori for her countless hours interviewing the participants and also translating the interview questions to Swahili and responses from Swahili to English. I also thank The Illala Municipal Council for approving the study. Thanks go to Dr. Mwanahamisi Hassan, Municipal Medical Officer of Health, Dr. Kibao and Dr. Simba. Much appreciated grant support came from the Ohio Wesleyan University TEW Presidential Discretionary Fund. 
Citation: Quaye R (2018) Scaling-Up Antiretroviral Therapy in Tanzania: Perspectives of Users. J AIDS Clin Res 9: 777. doi: 10.4172/21556113.1000777

Page 4 of 4

\section{References}

1. UNAIDS (2004) Report on the Global AIDS Epidemic . UNAIDS, Geneva.

2. Ministry of Health and Social Welfare (2008) Health Sector Reform: The United Republic Of Tanzania Dar es Salaam.

3. Russell S, Zalwango F, Seeley J (2015) The Framing and Fashioning of Therapeutic Citizenship Among People Living with HIV Taking Antiretroviral Therapy in Uganda. Qualitative Health Research 1: 1-12.
4. Mmbaga E, Dodo M, Leyna H, Moen K, Leshabari M (2012) Sexual Practices and Perceived Susceptibility to HIV Infection among Men Who Have Sex with Men in Dar es Salaam, Mainland Tanzania. AIDS and Clinical Research S1-12.

5. Cort D, TuHsin (2018) Safety in Stigmatizing?: Instrumental Stigma Beliefs and Protective Sexual behavior in Sub-Saharan Africa. Soc Sci Med 197: 144-152.

6. Bila B, Egrot M ( 2009) Gender Asymmetry in Health care- Facility Attendance of people Living with HIV/AIDS in Burkina Faso. Soc Sci Med 2: 1212-1234. 